\title{
Unbundling and Incumbent Investment in Quality Upgrades and Cost Reduction*
}

\author{
João Vareda \\ School of Economics, Universidade Nova de Lisboa ${ }^{\dagger}$ \\ Autoridade da Concorrência
}

November, 2007

\begin{abstract}
We study the investment of a telecommunications incumbent in quality and in cost reduction when an entrant can use its network through unbundling of the local loop. We find that unbundling may lower incentives for quality improvements, but raises incentives for cost reduction. Therefore, it is not true that all types of investment are crowded out with unbundling. If the regulator can commit to a socially optimal unbundling price before investment, the incumbent makes both types of investment. In the absence of commitment, the incumbent will not invest, so that unbundling regulation may lower welfare as compared to no regulation.
\end{abstract}

JEL classification: D92, L43, L51, L96

Keywords: Telecommunications Regulation, Unbundling, Investments, Quality upgrades, Cost reduction, Commitment.

${ }^{*}$ I gratefully acknowledge the helpful comments from Steffen Hoernig. I would also like to thank Pedro P. Barros, Michael Baye, Marc Bourreau, Marc Ivaldi, Martin Peitz, and the participants at the CEPR Applied IO School (Funchal, May 2006), at the QED Meeting (Vienna, May 2006), at the EARIE Conference (Amsterdam, August 2006), at the ZEW Summer Workshop on ICT (Mannheim, June 2007), at the Telecom Paris Conference on the Economics of ICT (Paris, June 2007), at the EEA Conference (Budapest, August 2007), at the ITS Regional Conference (Istanbul, September 2007), Zvi Eckstein and three anonymous referees for their comments and suggestions. Financial support from POCI 2010/FCT and FSE, and project POCTI/ECO/44146/2002 of FCT and FEDER. The opinions expressed in this article reflect only the author's views and in no way bind the institutions to which he is affiliated.

${ }^{\dagger}$ School of Economics, Universidade Nova de Lisboa, Campus de Campolide, 1099-032 Lisboa, Portugal. E-mail: jvareda@fe.unl.pt

${ }^{\ddagger}$ AdC, Rua Laura Alves n ${ }^{\circ} 4,4^{\circ}, 1050-038$ Lisboa, Portugal. 


\section{Introduction}

Unbundling and investment. In the last 10 years, mandatory unbundling has become a standard remedy proposal for solving the bottleneck problem in fixed telecoms competition. Since there are high entry barriers in the telecommunications market, because of scale economies, sunk costs and firstmover advantages, it is hard for a new operator to enter the market as a full-facility competitor. In particular, the building of local access networks, which are composed of circuits connecting end users to switches located in central offices, requires large investments in terms of money and time.

Under mandatory unbundling an incumbent firm has to share the use of some of its facilities with its competitors. This implies that an essential input is, at the wholesale level, separated from the incumbent's overall facilities, in order to allow for commercial wholesale supply of this input. In the particular case of local loop unbundling, this means that a new operator can directly plug into the incumbent's network by creating a connection from its switch to the incumbent's local access network.

This policy is promoted both in the United States since the 1996 Telecommunications Act and in the European Union since the 1998 liberalization, and is supposed to generate entry in the market, and to encourage entrants to build their own network in the future when their stock of costumers is large enough.

Service-based competition promoted by unbundling has, however, been criticized on the basis that it only promotes static efficiency. The main argument is that incumbents would not have incentives to invest if they had to share the benefits of their investments with rivals. Moreover, if access to the incumbents' network was allowed too easily, this would create inefficiencies in the long run since an entrant would not have incentives to build competing facilities (see Jorde et al., 2000).

Partially as a response to these arguments, several empirical studies analyzing the effect of unbundling on incumbent firms' investment have emerged. For instance, Willig et al. (2002) examine the relationship between unbundling prices and Bell companies' investments, and conclude that lower unbundling prices stimulate incumbents' investment, supporting a competitive stimulus hypothesis, according to which a low unbundling price encourages entry, and this increased competition strengths the incumbents' incentive to invest. A study by Hassett et al. (2003) obtains similar conclusions.

However, these results are not without controversy. Haring et al. (2002) criticize Willig's estimation methodology and develop their own econometric model. They obtain the opposite relationship, i.e. low unbundling prices 
reduce the profitability of incumbents' investment leading to a reduction in that investment. Hausman and Sidak (2005) corroborate this opinion in their case study about the unbundling experience in the US, New Zealand, Canada, United Kingdom, and Germany. Gabel and Huang's (2003) econometric results indicate that in the US the higher the unbundling price, the more likely is the introduction of new services by the incumbents. Ingraham and Sidak (2003) show that mandatory unbundling increases the volatility of the incumbents' stock returns, which increases their equity cost.

In 2003 a new controversy has emerged after the publication of the Phoenix Center Policy Bulletin $n^{\circ} 5$ which shows that the rise in unbundling lines has increased investment by incumbents. This gave origin to two replies, one by Hazlett et al. (2003) on behalf of Verizon, and another by Hill (2003) on behalf of Z-Tell-Communications, both contesting the empirical estimation and arguing that the rise in unbundling lines has led to a decline in incumbents' investment. As a response, the Phoenix Center published its Policy Bulletin $\mathrm{n}^{\circ} 6$ which, by incorporating the comments of the two replies, shows that its previous result was robust.

Finally, there is also a study by Chang et al. (2003) that finds, using US data, that lower access prices have spurred investment by incumbents. Even so, the same study points in the opposite direction for Europe.

We can conclude that there is an unresolved controversy about the true effect of unbundling in incumbents' investment and, following from this, what the regulated unbundling price should be.

Model and results. In this paper, we develop a theoretical model with two operators, an incumbent and an entrant, that compete in subscription prices. The entrant can only compete with the incumbent if it has access to its local loop, for which it must pay an unbundling price. Our model supposes partial consumer participation, therefore it portrays non-mature markets, such as the broadband market. Bourreau and Dogan (2005) assume full consumer participation represented by a Hotelling model. In this model profits are insensitive to the unbundling price for a large interval of unbundling prices, which does not seem to be reasonable in the context of investment choice.

The main contribution of our model is the comparison of the incumbent's incentives for two different types of investment, quality-upgrades and costreduction, when the regulator sets the unbundling price before investment. We show that, although these investments are complements, the direct effect of the unbundling price on each one differs. Indeed, a lower unbundling price decreases incentives for quality improvements, but raises incentives for cost 
reduction. This follows from the fact that, for a lower unbundling price, the incumbent wants to maintain its competitive advantage. Thus, it has more incentives to invest in cost reduction. On the other hand, it has less incentives to invest in quality upgrades because this benefits both operators. In equilibrium, we have a higher investment in cost reduction for a lower unbundling price, while investment in quality can be higher or lower depending on the strength of the complementarity effect.

Given this, we determine the socially optimal unbundling price, and show that when the regulator is able to commit to the unbundling price he should set a lower (higher) price when cost reduction is relatively less (more) expensive than quality upgrades.

Next, we analyze a context where the regulator cannot commit to his decisions and revises the unbundling price after the investment has been made. In this case, the incumbent does not invest since the regulator sets a price such that it earns zero profits gross of investment. Here unbundling crowds out investment, and thus social welfare is lower than in the commitment context.

Then, we compare the two scenarios with an unregulated market. We show that the incumbent has incentives to unbundle its infrastructure in order to attract new consumers to the market. This is always worse than the context where the regulator sets the unbundling price before investment as the price set by the incumbent is too high, but it can be better than a nocommitment context since there is some investment. Therefore, we conclude that the unbundling problem raised by some authors is more a problem of commitment rather than unbundling as such.

Finally, we consider two extensions to our model. First, we briefly analyze the case of imperfect commitment, i.e. a context where the regulator is able to commit with a probability lower than 1 , and argue that results are similar to the commitment context, although the incumbent has weaker incentives to invest. As a second extension, we provide a short analysis of the case of mature markets. In these markets, investment in quality upgrades increases with the unbundling price, while investment in cost reduction is independent of it. Thus, with full consumer participation we find a positive relationship between total investment and the unbundling price.

Related literature. In contrast with the large amount of research on static access pricing, the dynamic study of optimal access pricing is still in its early stages. Valletti (2003) reviews the static access pricing literature, and 
provides a discussion about the linkage between access pricing and investment incentives by relating them with questions common to R\&D. Guthrie (2006) provides a survey over the recent literature on the relationship between infrastructure investment and the different regulatory regimes.

Foros (2004) shows that under some conditions the investment level in quality is lower with price regulation since the access price is set equal to marginal cost. Kotakorpi (2006) considers a similar model with vertical differentiation, and obtains similar results. Cambini and Valletti (2004) study the impact of access charges on the incentives to invest in quality, but in a context of two-way access. They derive the result that firms would choose an access price above marginal cost in order to diminish each other's incentive to invest. Bourreau and Dogan (2005) consider the possibility of quality upgrades by the incumbent in an unregulated context, and when the entrant can invest in its own network, and show that the incumbent not always finds it profitable to invest. Vareda and Hoernig (2007) study the investment of two operators in a new infrastructure which allows them to offer new services.

In addition, there are some papers that consider cost-reducing investments, as Biglaiser and Ma (1999), Cabral and Riordan (1989) and Sappington (2002), the first in a context of an incumbent firm and the other two in monopoly.

The remainder of the paper is organized as follows. We describe the model in Section 2, and in Section 3 we obtain the equilibrium prices and quantities. In Section 4 and 5 we solve the investment and regulation stage when the regulator can commit to the unbundling price, and when he cannot, respectively. In Section 6 we find the unregulated market equilibrium, and in Section 7 we consider some extensions. Finally, in Section 8 we conclude.

\section{The Model}

We introduce a model of a telecommunications market, where two firms compete on subscription prices. The operators on this market are: one vertically integrated network (denoted as incumbent) which owns the local loop, and one non-integrated network (denoted as entrant) which only owns a backbone and switches, and needs access to the incumbent's local loop so that it can be able to compete. ${ }^{1}$

We introduce a third party, the regulator, who sets the local loop access price, which we will designate as unbundling price, in order to maximize

\footnotetext{
${ }^{1}$ Our results can also be applied to situations where the entrant has access to more unbundled elements of the incumbent's network, and not only to the local loop.
} 
social welfare. We assume that the unbundling price is the only instrument available for the regulator. This corresponds closely to the current European practice. Furthermore, we adopt the simplifying assumption of complete information, i.e. the regulator is supposed to have full information about the incumbent's technology and costs.

We assume that the incumbent can invest in its infrastructure both to increase quality and to reduce cost, and that there is no uncertainty about returns on investment.

After observing the price set by the regulator and the investment made by the incumbent, the entrant decides if it asks for access to the local loop. In this paper we exclude the possibility of entering as a facility-based competitor.

\section{Demand side}

Contrary to the Hotelling model often used in the literature, in our paper we assume partial consumer participation, which means that there is always some consumers who will not buy. This creates the opportunity to consider welfare effects neglected by the former model and makes profits depend on the unbundling price. We will then work with the following aggregate demand functions due to Bowley (1924): ${ }^{2}$

$$
\begin{gathered}
q_{I}=\frac{a(1-\theta)-p_{I}+\theta p_{E}}{b\left(1-\theta^{2}\right)} \\
q_{E}=\frac{a(1-\theta)-p_{E}+\theta p_{I}}{b\left(1-\theta^{2}\right)}
\end{gathered}
$$

where $\left(q_{i}, p_{i}\right)$ are the number of subscribers and the subscription price of operator $i$, with $i=I$ for the incumbent and $i=E$ for the entrant. Parameter $a$ corresponds to the reservation price, and $\theta \in(0,1)$ indicates the degree of substitutability between the services offered by the two operators. The higher is $\theta$, the stronger is the substitutability. For simplicity, we normalize $b=1$.

These demand functions can be derived by aggregation from a standard individual consumer model of vertical product differentiation with discrete choice: There are two groups of consumers, with one regarding the incumbent's product as being of higher quality, and the other regarding the entrant's product as being of higher quality. Consumers are uniformly distributed along an interval $[0,1]$ with a willingness to pay for quality that declines as they move from 0 to 1 (see Martin, 2002, p.81). Indeed, in a telecommunications market, consumers usually subscribe services from only one operator,

\footnotetext{
${ }^{2}$ This model of aggregate demand functions for differentiated products is widely used in the industrial organization literature (see Spence, 1976, for an example).
} 
thereby, they face a discrete decision problem of which operator to subscribe to.

The consumer surplus arising from aggregating the individual indirect utilities is of the form:

$$
C S=\frac{a^{2}}{1+\theta}+M+\frac{p_{I}^{2}+p_{E}^{2}}{2\left(1-\theta^{2}\right)}-\frac{a\left(p_{I}+p_{E}\right)}{1+\theta}-\frac{\theta p_{I} p_{E}}{1-\theta^{2}},
$$

where $M$ is the numeraire good. ${ }^{3}$

Note that by assuming that reservation prices are equal to both operators we are restricting the consumers of one group to regard the quality of operators (the preferred and the least preferred one) the same way as the other group regards. This assumption is made for analytical convenience, however, qualitatively results do not depend on it (at least until the difference between reservation prices is not too big).

\section{Supply side}

Regarding the incumbent's cost structure, we assume that cost per subscriber is just a constant marginal cost $c$. For simplicity, irrespective of being the incumbent or the entrant that sells the services to subscribers, we assume the incumbent's marginal cost per subscriber to be the same, and lower than the reservation price.

If the entrant decides to ask for access to the incumbent's local loop, the incumbent receives from the entrant the unbundling price $r$ per consumer. For its own retail services it receives a subscription price $p_{I}$ per consumer. Given these, in the absence of investment, the incumbent's profit is:

$$
\pi_{I}=\left(p_{I}-c\right) q_{I}+(r-c) q_{E} .
$$

The entrant receives a subscription price $p_{E}$ from its customers and pays the correspondent unbundling price to the incumbent. Hence, its profit is:

$$
\pi_{E}=\left(p_{E}-r\right) q_{E} .
$$

We assume that firms only operate in the market if they have non-negative profits:

$$
\pi_{I} \geq 0, \pi_{E} \geq 0
$$

As we are not considering in our model questions related with foreclosure, we assume that the entrant has already incurred in the sunk cost of entry. Thus, it asks for access if it is able to obtain non-negative retail profits.

\footnotetext{
${ }^{3}$ In the following we will consider that $M=0$ for simplicity.
} 


\section{Investments}

We will consider that the incumbent can make two types of investment: quality-upgrades and cost reduction.

In the first case, we assume that the investment increases the reservation price by $g$, which implies a parallel shift in both demand functions. In fact, as the entrant supplies its services through the incumbent's local network, it also benefits from this investment, consequently, the reservation price for its services also increases in $g$. We assume that spillovers are complete, contrary to Foros (2004) and Kotakorpi (2006). ${ }^{4}$ An example of this kind of investment is an upgrade of the switching equipment or the installation of new fibre optic cables, which allows to increase the transmission velocity or the capacity to deliver voice and data traffic. The investment cost function is quadratic:

$$
C_{q}(g)=\frac{\alpha}{2} g^{2}
$$

The second type is an investment to decrease the cost of providing the services. Examples are the reduction in the costs of installing ADSL, which usually requires a set of procedures, or the increase in the reliability of the local network. Since the entrant uses the incumbent's lines to supply the services to its subscribers, it is the incumbent that supports all the operating costs. Consequently, if the incumbent invests in cost reduction, the marginal cost of supplying all consumers is reduced, no matter whether they are the incumbent's or the entrant's. In this case, we assume that the innovation represents a decrease of $h$ in incumbent's marginal cost, and the investment cost function is also quadratic:

$$
C_{c}(h)=\frac{\beta}{2} h^{2} .
$$

\section{Regulator's decision}

The regulator maximizes social welfare, which is given by the sum of profits and consumer surplus:

$$
W=\pi_{I}+\pi_{E}+C S .
$$

This is the traditional welfare measure adopted by industrial organization theory. It can be argued that the regulator objective function should reflect the pressure suffered from the managers of firms they regulate by giving

\footnotetext{
${ }^{4}$ In these papers, an investment increases the willingness to pay for services, but the dimension of the effect depends on the ability of each operator to transform input to output. Thus, we can have the incumbent offering higher quality services, and vice-versa.
} 
more weight to firms' surplus. However, there are also theories which say that as the regulator is indirectly chosen by the firm's subscribers through the government electoral process, he should give more weight to consumer's surplus. Hence, we decide to adopt a balanced assumption. ${ }^{5}$

In terms of the regulator's decision timing, we will first consider a context where he sets the unbundling price at the beginning of the game, and commits to it until the end, as in Cambini and Valletti (2004). Although this may seem a strong assumption, it can be argued that the unbundling price set by the regulator provides some commitment. To give an example, the regulator can announce that it will set the unbundling price at a certain level for a certain period, for instance until the next review. In this case this timing makes sense: if the incumbent undertakes investments during the same period, it will take as given the unbundling price set by the regulator. Valletti (2003) argues that one of the main factors that must be taken into account on the delineation of regulatory policies is the fact that regulators should be able to commit to rules over a reasonable time period. Guthrie (2006) discusses the constraints on the regulator's actions adopted in several countries to prevent him from acting opportunistically. For instance, in US the separation of judiciary from government, the well-developed regulatory procedures, and the Constitution combine to restrict opportunism.

Later, we will consider a context where the regulator does not commit, and only takes the final decision about the unbundling price after the investment stage, as in Foros (2004) and Kotakorpi (2006). This may be due to legal, political and/or practical constraints on the regulator.

\section{Timing of the game}

1. The regulator fixes the unbundling price.

2. The incumbent decides how much to invest in its infrastructure.

3. The entrant decides if it asks for access.

4. Firms compete in prices.

When the regulator cannot commit to his decision the order of the first two moves is reversed.

We now find the Subgame-Perfect Equilibrium using backward induction.

\footnotetext{
${ }^{5}$ For a discussion about the regulator's objectives see Guthrie (2006).
} 


\section{Price competition stage}

For given reservation prices (and therefore quality levels) and cost levels, using demand functions (1) and (2), and maximizing profits with respect to subscription price, we obtain the following Nash-equilibrium prices and quantities of the price competition stage (see Appendix A):

$$
\begin{gathered}
p_{I}-c-h=\frac{1-\theta}{2-\theta}\left(x_{0}+g+h\right)+\frac{3 \theta}{4-\theta^{2}}\left(y_{0}+h\right) \\
p_{E}-r=\frac{1-\theta}{2-\theta}\left(x_{0}+g+h\right)-2 \frac{1-\theta^{2}}{4-\theta^{2}}\left(y_{0}+h\right) \\
q_{I}=\frac{1}{2-\theta^{2}+\theta}\left(x_{0}+g+h\right)-\frac{\theta}{4-\theta^{2}}\left(y_{0}+h\right) \\
q_{E}=\frac{1}{2-\theta^{2}+\theta}\left(x_{0}+g+h\right)-\frac{2}{4-\theta^{2}}\left(y_{0}+h\right),
\end{gathered}
$$

where $x_{0}=a-c$ and $y_{0}=r-c$. Parameter $y_{0}$ represents the incumbent's ex-ante access margin. It can also be interpreted as the entrant's cost disadvantage, since the entrant has to pay $r$ for each line while the incumbent only incurs a cost of $c$. In the future we will work with $y_{0}$ when we want to find the optimal unbundling price.

These equilibrium prices and quantities are only valid provided that the entrant asks for access, which is true if $q_{E} \geq 0$, or:

$$
y_{0} \leq \frac{1}{2} \frac{2+\theta}{1+\theta}\left(x_{0}+g+h\right)-h .
$$

In this case, firms' profit and welfare are:

$$
\begin{aligned}
\pi_{I}\left(g, h, y_{0}, \alpha, \beta\right) & =\frac{1}{(2-\theta)^{2}}\left(\frac{1-\theta}{1+\theta}\left(x_{0}+g+h\right)^{2}-\frac{8+\theta^{2}}{(2+\theta)^{2}}\left(y_{0}+h\right)^{2}\right. \\
& \left.+\frac{4-2 \theta+\theta^{2}}{2+\theta}\left(x_{0}+g+h\right)\left(y_{0}+h\right)\right)-\frac{\alpha}{2} g^{2}-\frac{\beta}{2} h^{2} \\
\pi_{E}\left(g, h, y_{0}, \alpha, \beta\right) & =\frac{1-\theta}{(2-\theta)^{2}}\left(\frac{1}{1+\theta}\left(x_{0}+g+h\right)^{2}+4 \frac{1+\theta}{(2+\theta)^{2}}\left(y_{0}+h\right)^{2}\right. \\
& \left.-\frac{4}{2+\theta}\left(x_{0}+g+h\right)\left(y_{0}+h\right)\right)
\end{aligned}
$$




$$
\begin{aligned}
W\left(g, h, y_{0}, \alpha, \beta\right) & =\frac{1}{(2-\theta)^{2}}\left(\frac{3-2 \theta}{1+\theta}\left(x_{0}+g+h\right)^{2}-\frac{1}{2} \frac{4+5 \theta^{2}}{(2+\theta)^{2}}\left(y_{0}+h\right)^{2}\right. \\
& \left.-\frac{1-\theta^{2}}{1+\theta}\left(x_{0}+g+h\right)\left(y_{0}+h\right)\right)-\frac{\alpha}{2} g^{2}-\frac{\beta}{2} h^{2}
\end{aligned}
$$

Otherwise, we have monopoly and profit and welfare are:

$$
\begin{gathered}
\pi_{I}^{M}(g, h, \alpha, \beta)=\frac{1}{4}\left(x_{0}+g+h\right)^{2}-\frac{\alpha}{2} g^{2}-\frac{\beta}{2} h^{2} \\
W^{M}(g, h, \alpha, \beta)=\frac{1}{2}\left(x_{0}+g+h\right)^{2}-\frac{\alpha}{2} g^{2}-\frac{\beta}{2} h^{2} .
\end{gathered}
$$

\section{Commitment to unbundling price before investment}

\subsection{Investment stage}

We will start to solve the incumbent's investment problem about how much to invest in quality upgrades and in cost reduction when the regulator acts as a first-mover, i.e. when the regulator can commit to the unbundling price set prior to investments.

Since the main focus of our paper is to determine the relationship between the unbundling price and investment, we only analyze here the investment decision when entry occurs, since otherwise it is impossible to observe any relationship. Besides, we will see in the next section that the socially optimal unbundling price the regulator should set is such that entry occurs.

Proposition 1 When entry occurs, the investments in quality upgrades and cost reduction are complements. Yet, the marginal profit of investing in quality upgrades (cost reduction) is increasing (decreasing) in the unbundling price.

Proof. From the derivatives of (15) we easily find that:

$$
\frac{\partial^{2} \pi_{I}}{\partial g \partial h}>0, \frac{\partial^{2} \pi_{I}}{\partial g \partial y_{0}}>0, \frac{\partial^{2} \pi_{I}}{\partial h \partial y_{0}}<0 .
$$

The higher is the investment in quality upgrades, the higher is the marginal benefit of investing in cost reduction, since it decreases the cost of serving a higher number of subscribers. Thus, investments are complements. 
With respect to the interactions between investments and the unbundling price, they take place both on the wholesale and on the retail component of the incumbent's profit. The interactions on the retail profit have the same signal for both investments. The higher is the unbundling price, the higher is the incumbent's subscription price, and thus the higher are the incentives to increase its number of subscribers by investing in cost reduction and in quality upgrades. However, the interactions on the wholesale component have opposite signals. When the unbundling price is higher, the incumbent earns more profit with the entrant's subscribers. As a consequence, it has a higher incentive to invest in quality upgrades since this increases the entrant's number of subscribers. On the other hand, it has less incentives to invest in cost reduction since this decreases its rival's number of subscribers. This follows from the fact that this investment only reduces incumbent's cost per line, while the entrant's cost per line, which is given by $r$, remains the same. Consequently, the incumbent's cost advantage over its rival increases.

Hence, given that wholesale interactions are stronger than retail interactions, we may observe each investment going in a different direction after a change in the unbundling price, despite the complementarity between the two investments.

If the regulator set an access margin instead of an unbundling price, so that $r$ decreased when $c$ decreased, the investment in cost reduction would be equivalent to an investment in quality upgrades, since there would not be any gains in terms of cost advantage after an investment in cost reduction.

From the derivatives of the incumbent's profit and welfare we also find that, whatever the unbundling price set by the regulator, the incumbent will never invest efficiently.

Proposition 2 For a given unbundling price, the incumbent's investment is sub-optimal from a social welfare point of view.

Proof. We find that for any $\left(g, h, y_{0}\right)$ such that entry occurs:

$$
\begin{gathered}
\frac{\partial W}{\partial h}-\frac{\partial \pi_{I}}{\partial h}=\frac{(1-\theta)\left(x_{0}+g+h\right)}{\left(4-\theta^{2}\right)(1+\theta)}>0 \\
\frac{\partial W}{\partial g}-\frac{\partial \pi_{I}}{\partial g}=\frac{2(2+\theta)\left(x_{0}+g+h\right)}{\left(4-\theta^{2}\right)(1+\theta)}-\frac{3(1+\theta)\left(y_{0}+h\right)}{\left(4-\theta^{2}\right)(1+\theta)}>0 .
\end{gathered}
$$

Therefore, and given that both differences are increasing on the other type of investment, the incumbent will always invest less than socially optimal. 
Given the unbundling price set by the regulator (which we assume to be such that entry is profitable), the incumbent maximizes its profit function (15) with respect to $g$ and $h$. The profit-maximizing investments in quality upgrades and in cost reduction are:

$$
\begin{aligned}
g^{*}\left(y_{0}, \alpha, \beta\right) & =\frac{\left(8+\theta^{3}\right)(1+\theta) \beta-(2+\theta)\left(6-\theta+\theta^{2}\right)}{V(\theta, \alpha, \beta)} y_{0} \\
& +\frac{\left(6-\theta+\theta^{2}\right)(2+\theta)+2(1-\theta)(2+\theta)^{2} \beta}{V(\theta, \alpha, \beta)} x_{0} \\
h^{*}\left(y_{0}, \alpha, \beta\right) & =-\frac{(1+\theta)\left(8+2 \theta^{2}-\theta^{3}\right) \alpha-(2+\theta)\left(6-\theta+\theta^{2}\right)}{V(\theta, \alpha, \beta)} y_{0} \\
+ & \frac{(2+\theta)\left(8-3 \theta^{2}+\theta^{3}\right)}{V(\theta, \alpha, \beta)} \alpha x_{0},
\end{aligned}
$$

where:

$$
\begin{aligned}
V(\theta, \alpha, \beta) & =(1+\theta)\left(4-\theta^{2}\right)^{2} \alpha \beta-(2+\theta)\left(6-\theta+\theta^{2}\right) \\
& -2(1-\theta)\left((2+\theta)^{2} \beta+\left(4+4 \theta-\theta^{3}\right) \alpha\right) .
\end{aligned}
$$

We assume that, for any $y_{0}$, the socially optimal quality upgrades and cost reduction investments are finite, which is equivalent to: ${ }^{6}$

$$
\begin{gathered}
\alpha>\underline{\alpha} \equiv \frac{6-4 \theta}{4-3 \theta^{2}+\theta^{3}} \\
\beta>\underline{\beta} \equiv \frac{(1-\theta)\left(12+8 \theta-\theta^{2}-2 \theta^{3}\right) \alpha+\left(7+3 \theta+7 \theta^{2}+\theta^{3}\right)}{(2+\theta)^{2}\left((2-\theta)^{2}(1+\theta) \alpha-(6-4 \theta)\right)} .
\end{gathered}
$$

If both these conditions hold, we have $V(\theta, \alpha, \beta)>0$, and $\left(h^{*}, g^{*}\right)$ maximize profits in case entry occurs. ${ }^{7}$

Given that we will later consider an unregulated context, we further assume that if the incumbent can additionally set the unbundling price, it will invest a finite amount, which is equivalent to: ${ }^{8}$

$$
\beta>\underline{\beta} \equiv \frac{(2+\theta)\left(6-\theta+\theta^{2}\right) \alpha}{2(1+\theta)\left(8+\theta^{2}\right) \alpha-(2+\theta)\left(6-\theta+\theta^{2}\right)} .
$$

\footnotetext{
${ }^{6}$ These guarantee that the Hessian of a social planner who takes the decisions regarding investments verifies the second-order conditions for a maximum.

${ }^{7}$ These guarantee that the Hessian of the incumbent's problem when entry occurs verifies the second-order conditions for a maximum. Yet, if we just impose $\left(h^{*}, g^{*}\right)$ to be finite the lower limits on $\alpha$ and $\beta$ would be smaller.

${ }^{8}$ This toghether with (23) and (24) guarantee that the Hessian of an incumbent that takes all decisions regarding investments and unbundling price verifies the second-order conditions for a maximum.
} 
We thus need to assure that:

$$
\beta>\beta_{\min } \equiv \max \{\underline{\beta}, \underline{\underline{\beta}}\} .
$$

However, for (20) and (21) to be the profit-maximizing investments we need to have the entrant asking for access to the incumbent's local loop. This only happens if:

$$
y_{0} \leq \frac{1}{2} \frac{2+\theta}{1+\theta}\left(x_{0}+g^{*}\left(y_{0}\right)+h^{*}\left(y_{0}\right)\right)-h^{*}\left(y_{0}\right),
$$

or

$y_{0} \leq \bar{y}_{0}(\alpha, \beta) \equiv \frac{(2-\theta)(2+\theta)^{2} \beta-\left(4+2 \theta-3 \theta^{2}\right) \alpha}{2\left(4-\theta^{2}\right)(1+\theta) \alpha \beta-(2+\theta)(4-\theta) \beta-\left(4+2 \theta-3 \theta^{2}\right) \alpha} x_{0}$,

which is positive for $\beta>\beta_{\min }$ and $\alpha>\underline{\alpha}$.

Note that (20) and (21) only hold if $h^{*} \leq c$. When $r$ is low enough, we may have $h^{*}>c$, which is equivalent to:

$$
\begin{aligned}
r< & \underline{r} \equiv \frac{(2+\theta)\left(8-3 \theta^{2}+\theta^{3}\right) \alpha}{(1+\theta)\left(8+2 \theta^{2}-\theta^{3}\right) \alpha-(2+\theta)\left(6-\theta+\theta^{2}\right)} a \\
& -\frac{(2+\theta)^{2}\left((1+\theta)(2-\theta)^{2} \alpha-2(1-\theta)\right) \beta}{(1+\theta)\left(8+2 \theta^{2}-\theta^{3}\right) \alpha-(2+\theta)\left(6-\theta+\theta^{2}\right)} c .
\end{aligned}
$$

In this case the best the incumbent can do is to invest $h^{* *}=c$, and the profit-maximizing investment in quality upgrades becomes:

$$
\begin{aligned}
g^{* *}\left(y_{0}, \alpha, \beta\right) & =\frac{2(1-\theta)}{(1+\theta)(2-\theta)^{2} \alpha-2(1-\theta)}\left(x_{0}+c\right) \\
& +\frac{(1+\theta)\left(4-2 \theta+\theta^{2}\right)}{\left((1+\theta)(2-\theta)^{2} \alpha-2(1-\theta)\right)(2+\theta)}\left(y_{0}+c\right) .
\end{aligned}
$$

Having found the equilibrium investments in quality upgrades and in cost reduction when entry occurs, we are now able to determine the effect of unbundling on each type of investment.

Proposition 3 When entry occurs, and for $r \geq \underline{r}$, the profit-maximizing investment in cost reduction is decreasing in the unbundling price. 
Proof. Taking the derivative of $h^{*}$ with respect to $r$, we obtain:

$$
\frac{\partial h^{*}}{\partial r}=\frac{\partial h^{*}}{\partial y_{0}} \frac{\partial y_{0}}{\partial r}=-\frac{(1+\theta)\left(8+2 \theta^{2}-\theta^{3}\right) \alpha-(2+\theta)\left(6-\theta+\theta^{2}\right)}{V(\theta, \alpha, \beta)},
$$

which is always negative for $\alpha>\underline{\alpha}$ and $\beta>\beta_{\min }$.

Proposition 4 Let $\widetilde{\alpha} \equiv \frac{172+50 \theta-17 \theta^{2}+16 \theta^{3}-8 \theta^{4}+2 \theta^{5}+\theta^{6}}{(1+\theta)\left(48+24 \theta-16 \theta^{2}-2 \theta^{3}-3 \theta^{4}+4 \theta^{5}-\theta^{6}\right)}$ and $\widetilde{\beta} \equiv \frac{6-\theta+\theta^{2}}{(1+\theta)\left(4-2 \theta+\theta^{2}\right)}$. When entry occurs, and for $r \geq \underline{r}$, the profit-maximizing investment in quality upgrades is increasing in the unbundling price if $\alpha \leq \widetilde{\alpha}$, or if $\alpha>\widetilde{\alpha}$ and $\beta>\widetilde{\beta}$. For $\alpha>\widetilde{\alpha}$ it is decreasing if $\beta \in\left(\beta_{\min }, \widetilde{\beta}\right)$.

Proof. Taking the derivative of $g^{*}$ with respect to $r$, we obtain:

$$
\frac{\partial g^{*}}{\partial r}=\frac{\partial g^{*}}{\partial y_{0}} \frac{\partial y_{0}}{\partial r}=\frac{\left(8+\theta^{3}\right)(1+\theta) \beta-(2+\theta)\left(6-\theta+\theta^{2}\right)}{V(\theta, \alpha, \beta)},
$$

which is positive for $\beta>\widetilde{\beta}$ and negative for $\beta<\widetilde{\beta}$. Then, comparing $\widetilde{\beta}$ with $\beta_{\text {min }}$, we always have $\widetilde{\beta}>\underline{\beta}$, but $\widetilde{\beta}>\underline{\beta}$ if and only if $\alpha>\widetilde{\alpha}$. Hence for $\alpha \leq \widetilde{\alpha}$, we have $\widetilde{\beta} \leq \beta_{\min }$.

As we have seen in Proposition 1, the higher is the unbundling price, the lower is the marginal profit of investing in cost reduction. Thus, as expected, we have a lower equilibrium investment in cost reduction.

In contrast, the effect of the unbundling price in equilibrium quality improvements does not follow immediately from Proposition 1, as only for a low $\alpha$ or a high $\beta$ we obtain a positive relationship. This results from the complementarity between the two investments. Indeed, if we take into account the indirect effect of a higher unbundling price through cost reduction, we observe that this has a negative impact on the marginal profit of quality improvements. Consequently, when this indirect effect is relatively stronger, we obtain a negative relationship between investment in quality upgrades and the unbundling price. This happens for a low $\beta$, i.e. when the reaction of cost reduction to an increase in the unbundling price is high.

The same indirect effect is present in the cost reduction equilibrium investment, but in this case the effect is weaker for all $\alpha>\underline{\alpha}$, and consequently, we always obtain a negative relationship. This follows from the fact that the marginal profit of cost reduction reacts more to changes in $r$ than the marginal profit of quality improvements.

For $r<\underline{r}$, cost reduction is independent of the unbundling price, while quality improvement is always increasing in $r$, since the indirect effect does 
not exist. However, for the rest of the paper, we will assume that $c$ is sufficiently high so that the lower limit $\underline{r}$ is never binding. In this case, we have (20) and (21) as the investment choices of the incumbent when entry occurs.

Proposition 5 Let $\Phi \equiv \frac{8+2 \theta^{2}-\theta^{3}}{8+\theta^{3}}$. When entry occurs, and $r \geq \underline{r}$, if $\frac{\beta}{\alpha}>\Phi$, the profit-maximizing total investment is increasing in the unbundling price and if $\frac{\beta}{\alpha}<\Phi$, it is decreasing.

Proof. Summing $g^{*}$ and $h^{*}$, and then taking the derivative with respect to $r$, we obtain:

$$
\frac{\partial\left(h^{*}+g^{*}\right)}{\partial y_{0}} \frac{\partial y_{0}}{\partial r}=(1+\theta) \frac{\left(8+\theta^{3}\right) \beta-\left(8+2 \theta^{2}-\theta^{3}\right) \alpha}{V(\theta, \alpha, \beta)}
$$

and thus $\frac{\partial\left(h^{*}+g^{*}\right)}{\partial r}>0$ if and only if $\beta>\frac{8+2 \theta^{2}-\theta^{3}}{8+\theta^{3}} \alpha$.

This result constitutes the main novelty of our paper, and helps to explain the discussed controversy about the relationship between the incumbent's investment and unbundling. According to this, if cost reduction is sufficiently expensive as compared with quality improvements, the higher is the unbundling price, the higher is the total amount of investment we expect the incumbent to do. Otherwise, we expect total investment to be lower when the unbundling price is higher.

The existent empirical studies do not distinguish between these two types of investment. By this way, it is natural that we observe some contradictory results. In fact, if $\frac{\beta}{\alpha}>\Phi$, a more intense utilization generated by a lower unbundling price leads an incumbent to invest less. Therefore, we expect to see more investment when the unbundling price is higher, which confirms the results of Haring et al. (2002), Hausman and Sidak (2005), and Gabel and Huang (2003). If $\frac{\beta}{\alpha}<\Phi$, we obtain a negative relationship between investment and unbundling price, which is according to the result by Willig et al. (2002), Hassett et al. (2003), and the Phoenix Center Studies (2003a, $2003 \mathrm{~b}$ ), which state that a lower unbundling price increases the intensity of competition, and this increases the incentives of an incumbent to invest in order to gain a competitive advantage.

Note that $\Phi>1$ for $\theta \in(0,1)$, i.e. we can have $\beta>\alpha$ and even so the relationship is negative. This is a consequence of the stronger direct effect of a higher unbundling price on cost reduction.

\subsection{Regulation stage}

After having determined the relationship between the incumbent's investment and unbundling in a context where the regulator is able to commit, we 
will now find the unbundling price the regulator should set ex ante.

Let us first consider the absence of an investment stage. In this case, the regulator maximizes social welfare over $r$ without having to take into account the incumbent's investment incentives. Yet, he must consider that the incumbent cannot earn negative profits.

Proposition 6 In the absence of an investment stage, the second-best socially optimal unbundling price is such that the incumbent earns zero profits and entry occurs.

\section{Proof. See Appendix B.}

It is socially optimal to have the incumbent subsidizing the entrant's activity through a negative access margin. In fact, when the unbundling price is lower than marginal cost, competition between operators is more intense. The incumbent wants the entrant to have fewer subscribers in order to lose less money with unbundled lines, and the entrant wants to have more subscribers because profit per subscriber is higher. As a result, the subscription price of both operators decreases, increasing social welfare.

When there is an investment stage and the regulator is able to commit to the unbundling price before investment, the regulator must take into account how the incumbent will invest given the unbundling price set ex ante. Again, he must consider that the incumbent's net profit at the profit-maximizing investment levels cannot be negative, i.e.

$$
\pi_{I}^{*}\left(y_{0}, \alpha, \beta\right)=\pi_{I}\left(g^{*}\left(y_{0}, \alpha, \beta\right), h^{*}\left(y_{0}, \alpha, \beta\right), y_{0}, \alpha, \beta\right) \geq 0 .
$$

First we observe that the regulator should promote service-based competition since the entry of a second operator has a strong effect on attracting more consumers to the market, which increases welfare. Therefore, he should set an unbundling price such that entry occurs.

The unbundling price should then be used for three objectives: to increase the intensity of competition, to give incentives for an investment in cost reduction and to give incentives for an investment in quality upgrades. When $\alpha>\widetilde{\alpha}$ and $\beta<\widetilde{\beta}$ the three objectives are all favored by a low $r$, and therefore the first-best unbundling price $\left(y_{0}^{c 1}\right)$ is so low that the incumbent would earn negative profits net of investment. In this case, the secondbest unbundling price $\left(y_{0}^{c 2}\right)$ that the regulator should set is such that the incumbent earns zero profits. Only for $\beta \geq \widetilde{\beta}$ quality improvements become 
increasing in $r$, and the regulator has incentives to set a higher $r$. However, if $\beta$ is lower than a threshold $\bar{\beta}(\alpha)>\widetilde{\beta}$, the first-best unbundling price is still such that the incumbent would earn negative profits net of investment. Therefore, the regulator should still set a second-best unbundling price. Only when $\beta>\bar{\beta}(\alpha)$, quality improvements gain enough weight relatively to cost reduction in the regulator's objective function, so that $y_{0}^{c 1}$ is sufficiently high to allow the incumbent to earn positive profits, and can thus be implemented by the regulator. If $\alpha$ is very high, then $y_{0}^{c 1}$ can never be implemented.

This can be summed up in the following proposition:

Proposition 7 Define $\bar{\alpha}$ as the lowest $\alpha$ such that

$$
\pi_{I}^{*}\left(y_{0}^{c 1}(\alpha, \beta), \alpha, \beta\right) \leq 0, \forall \beta>\beta_{\text {min }},
$$

and $\bar{\beta}(\alpha)$ by $\pi_{I}^{*}\left(y_{0}^{c 1}(\alpha, \beta), \alpha, \bar{\beta}\right)=0$ for $\alpha<\bar{\alpha}$. When the regulator sets the unbundling price before investment, at the socially optimal unbundling price entry occurs, and the incumbent earns zero profits (net of investment) if $\alpha \geq \bar{\alpha}$, or if $\alpha<\bar{\alpha}$ and $\beta \leq \bar{\beta}(\alpha)$, and positive profits (net of investment) if $\alpha<\bar{\alpha}$ and $\beta>\bar{\beta}(\alpha)$.

\section{Proof. See Appendix C.}

The socially optimal unbundling price induces the incumbent to invest more on the type of investment which has the lower cost. Even when the unbundling price is such that the incumbent earns zero profits, it invests, since otherwise it would earn negative profits.

\section{No commitment to unbundling price before investment}

In the previous section we have solved the regulator's and firms' problem when the regulator acts as a first-mover and sets the unbundling price before the incumbent invests. This commitment may, however, not be credible if the regulator can change price at will later on. In this case, he has all the incentives to revise his decision after observing the investment made by the incumbent, as in Foros (2004) and Kotakorpi (2006). Knowing this, the incumbent takes into account how the regulator will change his decision about the unbundling price when it invests.

We start by solving the regulator's problem. Given the value of $g$ and $h$ chosen by the incumbent in the first stage, the regulator maximizes social welfare with respect to $r$. 
Proposition 8 When the regulator sets the unbundling price after the investment decision, it is such that the incumbent earns zero profits (gross of investment), and entry occurs.

Proof. Given that the regulator takes his decision after investment, investment costs are already a sunk cost. Hence, the regulator's decision is similar to the no-investment benchmark.

Corollary 9 The incumbent does not invest in its network if the regulator only sets the unbundling price ex post. Therefore, welfare is lower as compared with the commitment context.

Proof. The first part of the Proposition follows from Proposition 8, since if the incumbent invests it will earn negative net profits. The access margin set by the regulator is then the same as in the no-investment benchmark, and social welfare is $W^{n c}=W^{n i}$, as defined in Appendix B. Finally, one can prove that $W^{n c}<W^{c}(\alpha, \beta)$, as defined in Appendix $\mathrm{C}$ for all $\alpha>\underline{\alpha}$ and $\beta>\beta_{\min }$. In fact, under commitment the regulator could set this unbundling price, and we would still have investment.

When the regulator acts as a second-mover, he only cares for low equilibrium prices, which are favoured by a low unbundling price. The incumbent foresees this behavior by the regulator, and thus it does not invest. In fact, if the incumbent invests, it will earn negative profits net of investment, because when the regulator sets the final unbundling price he treats investment costs as sunk costs. ${ }^{9}$

Note that, in this case, we cannot observe any relationship between the unbundling price and investment. What we observe is that under unbundling there is no investment.

If a regulator cannot commit to his decisions, unbundling policies affect welfare negatively. This result supports the criticisms of service-based competition, namely of its impact on dynamic efficiency. Indeed, if a regulator is implementing an unbundling policy he must show to the market participants that he has the ability to commit to his decisions. If he cannot commit, it may be better to leave the market unregulated as we will see next.

\footnotetext{
${ }^{9}$ In Foros (2004) and Kotakorpi (2006) instead of a zero profit restriction on the incumbent's profit, its is assumed that the access margin cannot be negative. Hence, the incumbent invests since it is able to retain part of the gains from its investment.
} 


\section{Unregulated market}

When there is no mandatory unbundling, the incumbent takes all decisions regarding investment and unbundling price. In this case, a high $r$ is equivalent to no unbundling.

As we have a simultaneous decision over $(r, g, h)$, by the envelope theorem, we just need to substitute the optimal investment functions $g^{*}\left(y_{0}, \alpha, \beta\right)$ and $h^{*}\left(y_{0}, \alpha, \beta\right)$ into the incumbent's profit function, and then maximize it with respect to $r$. The profit-maximizing ex-ante access margin becomes:

$$
y_{0}^{u r}=(2+\theta) \frac{(1+\theta)\left(4-2 \theta+\theta^{2}\right) \beta-\left(6-\theta+\theta^{2}\right)}{T(\theta, \alpha, \beta)} \alpha x_{0},
$$

where

$$
T(\theta, \alpha, \beta)=2(1+\theta)\left(8+\theta^{2}\right) \beta \alpha-(2+\theta)\left(6-\theta+\theta^{2}\right)(\beta+\alpha),
$$

which is positive for $\beta>\beta_{\min }$. Then, substituting $y_{0}^{u r}$ into $g^{*}\left(y_{0}, \alpha, \beta\right)$ and $h^{*}\left(y_{0}, \alpha, \beta\right)$, we find the profit-maximizing investments:

$$
\begin{aligned}
g^{u r} & =\frac{(2+\theta)\left(6-\theta+\theta^{2}\right) \beta}{T(\theta, \alpha, \beta)} x_{0} \\
h^{u r} & =\frac{(2+\theta)\left(6-\theta+\theta^{2}\right) \alpha}{T(\theta, \alpha, \beta)} x_{0} .
\end{aligned}
$$

Proposition 10 The incumbent prefers to rent out its loops to remaining a monopolist.

Proof. See Appendix D.

The incumbent unbundles its network in order to attract more consumers to the market. Then, it sets a high unbundling price to absorb part of the profit the entrant earns with these new subscribers, increasing its own profit.

There are some cases where incumbents have voluntarily entered into agreements with entrants for unbundled access, take the example of Verizon and Covad in the US.

Proposition 11 The profit-maximizing unbundling price is higher than the socially optimal one in a commitment context. Therefore, for $\alpha>\widetilde{\alpha}$ and $\beta<\widetilde{\beta}$ the incumbent invests less in both types of investment in an unregulated market, while otherwise it invests more in quality upgrades and less in cost reduction. Social welfare is always lower as compared to a commitment context. 
Proof. One can prove that, for $\alpha>\underline{\alpha}$ and $\beta>\beta_{\min }$, we have $y_{0}^{u r}(\alpha, \beta)>$ $y_{0}^{c}(\alpha, \beta)$ as defined in Appendix $\mathrm{C}$. The second part then follows from Propositions 3 and 4 . As for the welfare result, we just need to observe that the regulator could always have chosen $y_{0}^{u r}(\alpha, \beta)$ when he set the socially optimal unbundling price.

Proposition 12 Denote $W^{u r}(\alpha, \beta)$ as welfare at $\left(y^{u r}, g^{u r}, h^{u r}\right)$, and define $\alpha^{*}$ as the highest $\alpha$ such that $W^{u r}(\alpha, \beta) \geq W^{n c}$ for every $\beta>\beta_{\min }$, and $\beta^{*}(\alpha)$ as the highest $\beta$ such that $W^{u r}\left(\alpha, \beta^{*}\right)=W^{n c}$ for $\alpha>\alpha^{*}$. The profitmaximizing unbundling price is higher than the socially optimal one in the no-commitment context, and the incumbent invests more in both types of investment. Social welfare is higher as compared to the no-commitment context if $\alpha<\alpha^{*}$, or if $\alpha>\alpha^{*}$ and $\beta<\beta^{*}(\alpha)$. For $\alpha>\alpha^{*}$, it is lower if $\beta>\beta^{*}(\alpha)$.

\section{Proof. See Appendix E.}

If the regulator can commit to his decisions, social welfare is higher when he intervenes in the market ex ante as compared to no intervention since the unbundling price the incumbent would set is too high as compared to the one set by the regulator. Hence, in this case, it is better to have the regulator intervening.

On the other hand, if we compare the unregulated market with the context where the regulator cannot commit, the profit-maximizing unbundling price is still higher, but the incumbent's investments are also higher, similarly to Kotakorpi (2006). Therefore, when investment costs are low, it is preferable to leave the market unregulated since the incumbent unbundles and invests, while with ex-post regulation we obtain a zero investment. For $\beta>\beta^{*}(\alpha)$ and $\alpha \geq \alpha^{*}$ the investments made by the unregulated incumbent are lower, and thus regulation ex post becomes preferable since it assures low subscription prices.

\section{Extensions}

\subsection{Imperfect commitment to unbundling price}

Although we just analyze the cases of perfect commitment and no commitment, we could also have considered a context where the regulator could only stick to the unbundling price set ex ante with probability $\lambda$, and changed it ex post with probability $1-\lambda$. This, besides embracing our two extreme scenarios, would also include intermediate cases of imperfect commitment. ${ }^{10}$

\footnotetext{
${ }^{10}$ I would like to thank an anonymous referee for this suggestion.
} 
Given that the regulator considers investment costs as sunk costs when he does not commit to the unbundling price, he sets $r$ at a value such that the incumbent earns negative profits net of investment, as in Section 5. Hence, with imperfect commitment, the incumbent's expected profit would be:

$$
\begin{aligned}
\Pi_{I}\left(g, h, y_{0}, \lambda, \alpha, \beta\right)= & \lambda \pi_{I}\left(g, h, y_{0}, \alpha, \beta\right)+(1-\lambda)\left(-\frac{\alpha}{2} g^{2}-\frac{\beta}{2} h^{2}\right) \\
= & \frac{\lambda}{(2-\theta)^{2}}\left(\frac{1-\theta}{1+\theta}\left(x_{0}+g+h\right)^{2}-\frac{8+\theta^{2}}{(2+\theta)^{2}}\left(y_{0}+h\right)^{2}\right. \\
& \left.+\frac{4-2 \theta+\theta^{2}}{2+\theta}\left(x_{0}+g+h\right)\left(y_{0}+h\right)\right)-\frac{\alpha}{2} g^{2}-\frac{\beta}{2} h^{2} .
\end{aligned}
$$

and therefore its maximization problem would become:

$$
\max _{g, h} \Pi_{I}\left(g, h, y_{0}, \lambda, \alpha, \beta\right) .
$$

The results of the investment stage would come very similar to the commitment case since the incumbent would still have some investment incentives, although weaker than under perfect commitment. In fact, we have:

$$
\frac{\partial^{2} \Pi_{I}}{\partial g \partial \lambda}>0, \frac{\partial^{2} \Pi_{I}}{\partial h \partial \lambda}>0
$$

i.e. investment incentives are increasing in $\lambda$, meaning that the incumbent invests more the higher the regulator's commitment ability, since it can retain the gains from its investment more often.

When setting the unbundling price ex ante, the regulator should take $\Pi_{I}\left(g, h, y_{0}, \lambda, \alpha, \beta\right)$ into account for the restriction on the incumbent's profit, which means that if he wants the incumbent to invest he should leave it with positive profits for the state where the unbundling price remains stick, to compensate the negative profits when he changes it. Welfare would obviously be increasing in $\lambda$.

\subsection{Mature markets}

In this section we analyze the case of mature markets. This is important because it is another factor that can help to justify the contradictory empirical results about the effect of unbundling on incumbent's investment, since depending on the market coverage the relationship may differ.

In mature markets, we usually have full consumer participation, which means that total demand is perfectly inelastic with respect to price changes. A relevant example is fixed telephony. 
De Bijl and Peitz (2004) show that, contrary to the context of partial consumer participation, an increase in the unbundling price is totally passed on by the entrant to consumers. Bourreau and Dogan (2005) show that this is only true when the marginal consumer obtains positive surplus, which happens for low values of $r$.

Bourreau and Dogan (2005) use a Hotelling model to formalize a mature market, where, in equilibrium, each operator is located at one of the extremes of the line. In their model the incumbent's profit and social welfare are given by:

$$
\pi_{I}=\left\{\begin{array}{lll}
\frac{1}{2}+r-c & \text { if } & r \in\left[0, a-\frac{5}{4}\right) \\
\frac{1}{2}\left(a-\frac{1}{4}+r\right)-c & \text { if } \quad r \in\left[a-\frac{5}{4}, a-\frac{3}{4}\right) \\
r-1+\sqrt{3} \sqrt{a-r}-\frac{2 \sqrt{3}}{9}(a-r)^{\frac{3}{2}}-c & \text { if } \quad r \in\left[a-\frac{3}{4}, a\right)
\end{array}\right.
$$

and

$$
W=\left\{\begin{array}{lll}
a-\frac{1}{12}-c & \text { if } & r \in\left[0, a-\frac{3}{4}\right) \\
\frac{2}{3} a+\frac{1}{3} r-\frac{1}{3}-c+\frac{\sqrt{3}}{3} \sqrt{a-r} & \text { if } \quad r \in\left[a-\frac{3}{4}, a\right)
\end{array},\right.
$$

where $a>3$ is the fixed utility of consumption. ${ }^{11}$

Let us first consider an investment in quality. As in previous sections this investment increases the reservation price $a$. In this case, when the unbundling price is low $\left(r<a-\frac{5}{4}\right)$ the incumbent has no incentive to invest since the increase in quality is totally passed on to consumers as prices remain stick. For intermediate values of $r$ the incumbent invests in quality upgrades because this increases the valuation of the marginal consumer, allowing firms to increase prices. For high values of $r$ the incumbent invests even more, and the investment is increasing in $r$. In fact, as for $r>a-\frac{3}{4}$ the entrant's market share increases when the incumbent invests, the higher is $r$ the higher is the incentive to invest.

As concerns cost reduction, the incumbent always invests, but the size of the investment is independent of the unbundling price. This is because the number of subscribers is fixed, and translates into the lack of interaction between $r$ and $c$ in $\pi_{I}$.

We can then conclude that for a full consumer participation model total investment depends positively on the unbundling price for a sufficiently high unbundling price.

\footnotetext{
${ }^{11}$ In this model it is assumed that consumers face a transportation cost equal to 1.
} 


\section{Conclusions}

The main objective of this paper is to clarify the contradictory results in the empirical literature about the effects of unbundling on incumbent firms' investment. We develop a model with two telecommunications operators, an incumbent and an entrant, that offer differentiated services in a market with partial consumer participation. The incumbent can invest in quality upgrades and in cost reduction, which are complements but have different impacts on both firms. We conclude that both empirically observed relationships are possible. In fact, in a context where the regulator sets the unbundling price before investment, a low unbundling price increases the intensity of competition, which gives incentives for an incumbent to invest in cost reduction in order to gain a cost advantage for a given unbundling price. On the other hand, it decreases the incumbent's return from investing in quality upgrades. Thus, although one should expect to have both investments moving together due to their complementarity, it is not obvious what the equilibrium effect of a lower unbundling price on total investment will be.

We then compare social welfare when the regulator can commit to an unbundling price set ex ante and when he cannot. We show that in the latter case the incumbent does not invest since it does not retain any gain from its investments. As a consequence, social welfare is lower. Here, it may be better to leave the market unregulated since the incumbent firm will unbundle its local loop and invest. Thus, for the welfare effects of unbundling policies it is decisive whether the regulator can or cannot commit to unbundling prices.

Finally, we show that in case of imperfect commitment by the regulator the relationship between the unbundling price and incumbent's investment remains similar to the commitment case, while with mature markets it is positive for a sufficiently high unbundling price.

\section{Appendix A}

Given demand functions (1) and (2), the incumbent's and entrant's profit functions become:

$$
\begin{gathered}
\pi_{I}=\left(\frac{a(1-\theta)-p_{I}+\theta p_{E}}{1-\theta^{2}}\right)\left(p_{I}-c\right)+\left(\frac{a(1-\theta)-p_{E}+\theta p_{I}}{1-\theta^{2}}\right)(r-c) \\
\pi_{E}=\left(p_{E}-r\right)\left(\frac{a(1-\theta)-p_{E}+\theta p_{I}}{1-\theta^{2}}\right) .
\end{gathered}
$$


If we maximize each profit function with respect to the price of the respective operator, we obtain the following best response functions:

$$
\begin{aligned}
p_{I} & =\frac{1}{2}(a+c)(1-\theta)+\frac{1}{2} \theta p_{E}+\frac{1}{2} \theta r \\
p_{E} & =\frac{1}{2} a(1-\theta)+\frac{1}{2} \theta p_{I}+\frac{1}{2} r .
\end{aligned}
$$

Solving these, equilibrium prices become:

$$
\begin{aligned}
p_{I} & =\frac{1-\theta}{2-\theta}(a-c)+\frac{3 \theta}{4-\theta^{2}}(r-c)+c \\
p_{E} & =\frac{1-\theta}{2-\theta}(a-c)-2 \frac{1-\theta^{2}}{4-\theta^{2}}(r-c)+r .
\end{aligned}
$$

Substituting both in (1) and (2) we find equilibrium quantities:

$$
\begin{aligned}
q_{I} & =\frac{1}{2-\theta^{2}+\theta}(a-c)-\frac{\theta}{4-\theta^{2}}(r-c) \\
q_{E} & =\frac{1}{2-\theta^{2}+\theta}(a-c)-\frac{2}{4-\theta^{2}}(r-c) .
\end{aligned}
$$

Therefore, equilibrium profits and welfare are:

$$
\begin{aligned}
\pi_{I} & =\frac{1-\theta}{(1+\theta)(2-\theta)^{2}}(a-c)^{2}-\frac{8+\theta^{2}}{\left(4-\theta^{2}\right)^{2}}(r-c)^{2} \\
& +\frac{4-2 \theta+\theta^{2}}{(2-\theta)\left(4-\theta^{2}\right)}(a-c)(r-c) \\
\pi_{E} & =\frac{1-\theta}{(1+\theta)(2-\theta)^{2}}(a-c)^{2}+\frac{4\left(1-\theta^{2}\right)}{\left(4-\theta^{2}\right)^{2}}(r-c)^{2} \\
& -\frac{4(1-\theta)}{(2-\theta)^{2}(2+\theta)}(a-c)(r-c) \\
W & =\frac{3-2 \theta}{(1+\theta)(2-\theta)^{2}}(a-c)^{2}-\frac{4+5 \theta^{2}}{2\left(4-\theta^{2}\right)^{2}}(r-c)^{2} \\
& -\frac{1-\theta}{(2-\theta)^{2}}(a-c)(r-c) .
\end{aligned}
$$

Finally, when we introduce the two investments into the equilibrium we obtain $a+g$ instead of $a$, and $c-h$ instead of $c$. We also have to introduce the investment cost functions (7) and (8) into welfare and incumbent's profit. 


\section{Appendix B - Proof of Proposition 6}

The regulator maximizes social welfare subject to the non-negativity condition in the incumbent's profit. Thus, we have the following Lagrangian:

$$
£=W\left(y_{0}, \alpha, \beta\right)+\lambda_{1} \pi_{I}\left(y_{0}, \alpha, \beta\right) .
$$

First-order conditions are:

$$
\begin{gathered}
-2 \frac{(1-\theta)(2+\theta)^{2} x_{0}+\left(4+5 \theta^{2}\right) y_{0}}{\left(4-\theta^{2}\right)^{2}}+\lambda_{1} \frac{\left(8+\theta^{3}\right) x_{0}-2 y_{0}\left(8+\theta^{2}\right)}{\left(4-\theta^{2}\right)^{2}}=0 \\
\pi_{I}\left(y_{0}, \alpha, \beta\right) \geq 0 \quad, \quad \lambda_{1} \geq 0 \quad, \quad \pi_{I}\left(y_{0}, \alpha, \beta\right) \lambda_{1}=0 .
\end{gathered}
$$

If $\lambda_{1}=0$, we obtain:

$$
y_{0}=-\frac{(1-\theta)(2+\theta)^{2}}{4+5 \theta^{2}} x_{0}
$$

but this violates $\pi_{I}\left(y_{0}, \alpha, \beta\right) \geq 0$ restriction.

If $\lambda_{1}>0$, we obtain $\pi_{I}\left(y_{0}, \alpha, \beta\right)=0$, and thus (40) becomes:

$$
\lambda_{1}=2 \frac{x_{0}(1-\theta)(2+\theta)^{2}+\left(4+5 \theta^{2}\right) y_{0}}{\left(8+\theta^{3}\right) x_{0}-2 y_{0}\left(8+\theta^{2}\right)}>0 .
$$

Therefore, in the absence of investment, the socially optimal access margin is.

$$
y_{0}^{n i}=(2+\theta) \frac{(1+\theta)\left(4-2 \theta+\theta^{2}\right)-(2-\theta) \sqrt{(2+\theta)(1+\theta)\left(6-\theta+\theta^{2}\right)}}{2(1+\theta)\left(8+\theta^{2}\right)} x_{0} \text {. }
$$

Finally, we verify that the entrant asks for access since $y_{0}^{n i}<\frac{1}{2} \frac{2+\theta}{1+\theta} x_{0}$, and that social welfare:

$$
\begin{aligned}
W^{n i} & =\left(\frac{\left(128+16 \theta+22 \theta^{2}-4 \theta^{3}+3 \theta^{4}-3 \theta^{5}\right)}{4(1+\theta)\left(8+\theta^{2}\right)^{2}}\right. \\
& \left.+\frac{\left(24+6 \theta^{2}-3 \theta^{3}\right) \sqrt{(2+\theta)(1+\theta)\left(6-\theta+\theta^{2}\right)}}{4(1+\theta)\left(8+\theta^{2}\right)^{2}}\right) x_{0}^{2},
\end{aligned}
$$

is higher than $W^{M}=\frac{1}{2} x_{0}^{2}$.

\section{Appendix C - Proof of Proposition 7}


First, we substitute the profit-maximizing investments (20) and (21) into the welfare function (17) and then maximize it with respect to $y_{0}$. We obtain the first-best access margin $y_{0}^{c 1}=Z(\theta, \alpha, \beta) x_{0}$, where $Z(\theta, \alpha, \beta)$ is an nonlinear function.

Introducing $y_{0}^{c 1}(\alpha, \beta)$ into (31), we find that:

$$
\pi_{I}^{*}\left(y_{0}^{c 1}(\alpha, \beta) \alpha, \beta\right) \geq 0,
$$

if and only if $\beta \geq \bar{\beta}(\alpha)$ and $\alpha \leq \bar{\alpha}$. Thus, for $\beta \geq \bar{\beta}(\alpha)$ and $\alpha \leq \bar{\alpha}$, it is possible to implement $y_{0}^{c 1}(\alpha, \beta)$. However, if $\alpha>\bar{\alpha}$, or if $\alpha \leq \bar{\alpha}$ and $\beta<\bar{\beta}(\alpha)$ :

$$
\pi_{I}^{*}\left(y_{0}^{c 1}(\alpha, \beta), \alpha, \beta\right)<0,
$$

and therefore, the regulator can only implement the second-best ex-ante access margin which is obtained by solving $\pi_{I}^{*}\left(y_{0}^{c 2}, \alpha, \beta\right)=0$. From this we obtain $y_{0}^{c 2}=L(\theta, \alpha, \beta) x_{0}$, where $L(\theta, \alpha, \beta)$ is also a non-linear function.

Next we verify that $y_{0}^{c}(\alpha, \beta)<\bar{y}_{0}(\alpha, \beta)$ holds for $\alpha>\underline{\alpha}$ and $\beta>\beta_{\min }$, where $y_{0}^{c}(\alpha, \beta)=\max \left\{y_{0}^{c 1}(\alpha, \beta), y_{0}^{c 2}(\alpha, \beta)\right\}$. Thus, if entry is suppose to occur, the socially optimal ex-ante access margin is $y_{0}^{c}(\alpha, \beta)$ and welfare is $W^{c}(\alpha, \beta)$.

Finally, we need to check if the regulator does not prefer a monopoly context. A monopolist incumbent solves the following problem:

$$
\max _{g, h} \frac{1}{4}\left(x_{0}+h+g\right)^{2}-\frac{\alpha}{2} g^{2}-\frac{\beta}{2} h^{2},
$$

which gives optimal investments under monopoly:

$$
g^{M}=\frac{\beta}{2 \alpha \beta-\alpha-\beta} x_{0}, \quad h^{M}=\frac{\alpha}{2 \alpha \beta-\alpha-\beta} x_{0} .
$$

Substituting in (19), welfare under monopoly becomes:

$$
W^{M}(\alpha, \beta)=\frac{1}{2} \frac{\alpha \beta(3 \alpha \beta-\alpha-\beta)}{(2 \alpha \beta-\alpha-\beta)^{2}} x_{0}^{2} .
$$

One can prove that $W^{c}(\alpha, \beta)>W^{M}(\alpha, \beta)$ for $\alpha>\underline{\alpha}$ and $\beta>\beta_{\min }$, and therefore $y_{0}^{c}(\alpha, \beta)$ is the socially optimal unbundling price.

Omitted calculations are available from author.

\section{Appendix D - Proof of Proposition 10}

After tedious calculation one can prove that $y_{0}^{u r}(\alpha, \beta)<\bar{y}_{0}(\alpha, \beta)$ for $\alpha>\underline{\alpha}$ and $\beta>\beta_{\min }$, and thus the entrant asks for access. We can then 
introduce $y^{u r}, g^{u r}$ and $h^{u r}$ into the incumbent's profit function and obtain:

$$
\pi_{I}^{u r}(\alpha, \beta)=\frac{(2+\theta)\left(6-\theta+\theta^{2}\right) \alpha \beta}{2 T(\theta, \alpha, \beta)} x_{0}^{2} .
$$

Given $\left(g^{M}, h^{M}\right)$ find in Appendix C, the incumbent's monopoly profit is:

$$
\pi_{I}^{M}(\alpha, \beta)=\frac{1}{2}\left(\frac{\alpha \beta}{2 \alpha \beta-\alpha-\beta}\right) x_{0}^{2} .
$$

Comparing it with profit under unbundling, we find that $\pi_{I}^{u r}(\alpha, \beta) \geq$ $\pi_{I}^{M}(\alpha, \beta)$, for $\alpha>\underline{\alpha}$ and $\beta>\beta_{\min }$.

\section{Appendix E - Proof of Proposition 12}

If we substitute (32), (34), (35) into (17), we obtain welfare in an unregulated market:

$$
\begin{aligned}
W^{u r}(\alpha, \beta) & =\left(\frac{(1+\theta)\left(304+48 \theta+108 \theta^{2}+16 \theta^{3}+11 \theta^{4}-\theta^{5}\right) \beta \alpha}{T(\theta, \alpha, \beta)^{2}}\right. \\
& \left.-\frac{(\beta+\alpha)(2+\theta)^{2}\left(6-\theta+\theta^{2}\right)^{2}}{T(\theta, \alpha, \beta)^{2}}\right) \frac{1}{2} \alpha \beta x_{0}^{2} .
\end{aligned}
$$

Comparing with welfare in the no-commitment context, we find that if $\alpha<\alpha^{*}$, then $W^{u r}(\alpha, \beta)>W^{n c}$ for every $\beta>\beta_{\min }$. If $\alpha>\alpha^{*}$, then $W^{u r}(\alpha, \beta)>W^{n c}$ only if $\beta \in\left(\beta^{* *}(\alpha), \beta^{*}(\alpha)\right)$. One can show that for $\alpha>\alpha^{*}$, we have $\beta^{*}(\alpha)>\beta_{\min }>\beta^{* *}(\alpha)$ (calculations are available from author).

\section{References}

Biglaiser, G., and MA, C-T, 1999, "Investment Incentives of a Regulated Dominant Firm" Journal of Regulatory Economics, 16, 215-235.

Bourreau, M., and Dogan, P., 2005, "Unbundling the Local Loop", European Economic Review, 49, 173-199.

Bowley, A.L., 1924, "The Mathematical Groundwork of Economics", Oxford University Press.

Cabral, L., and Riordan, R., 1989, "Incentives for Cost-Reduction under Price-Cap Regulation", Journal of Regulatory Economics, 1, 93-102. 
Cambini, C., and Valletti, T., 2004, "Access Charges and Quality Choice in Competing Networks", Information Economics and Policy, 16, 391-409.

Chang, H., Koski, H., and Majumdar, S.K., 2003, "Regulation and Investment Behavior in the Telecommunications Sector: Policies and Patterns in US and Europe", Telecommunications Policy, 27, 677-699.

De BiJl, P., and Peitz, M., 2004, "Unbundling the Local Loop: one way access and imperfect competition" In: Dewenter, R., Haucap, J. (Eds.), Access Pricing: Theory and Practice, Elsevier Science.

Foros, O., 2004, "Strategic Investments with Spillovers, Vertical Integration and Foreclosure in the Broadband Access Market", International Journal of Industrial Organization, 22, 1-24.

Gabel, D.J., and HuAnG, G-L, 2003, "Promoting Innovation: Impact of Local Competition and Regulation of Deployment of Advanced Telecommunications Services for Businesses" draft, Internet and Telecom Convergence Program. MIT, Cambridge, MA.

Guthrie, G., 2006, "Regulating Infrastructure: The Impact on Risk and Investment", Journal of Economic Literature, 44, 925-972.

Haring, J., Rettle, M.L., Rohlfs, J.H., and Shooshan III, H.M., 2002, "UNE Prices and Telecommunications Investment", Strategic Policy Research 2002 .

Hassett, K.A., Ivanova, Z., Kotlikoff, L.J., 2003, "Increased Investment, Lower Prices - The Fruits of Past and Future Telecom Competition", mimeo.

Hausman, J., and SidAK, J., 2005, "Did mandatory unbundling achieve its purpose? Empirical evidence from five countries", Journal of Competition Law and Economics, 1, 173-245.

Hazlett, T.W., Havenner, A.M., and Bazelon, C., 2003, "Declaration of Thomas W. Hazlett, Arthur M. Havenner, and Coleman Bazelon: In the Matter of Petition for Expedited Forbearance from the Current Pricing Rules for the Unbundled Network Element Platform", U.S. F.C.C. W.C. Docket $\mathrm{N}^{\circ}$ 03-157.

HiLl, C., 2003, "Declaration of R.Carter Hill: In the Matter of Petition for Forbearance from the Current Pricing Rules for the Unbundled Network Element Platform", U.S. F.C.C. WC Docket No 03-157. 
Ingraham, S., and Sidak, J., 2003, "Mandatory Unbundling, UNE-P, and Cost of Equity: Does TELRIC Pricing Increase Risk for Incumbent Local Exchange Carriers?", Criterion Economics, Cambridge, MA.

Jorde, T.M., Sidak, J.G., and Teece, D.J, 2000, "Innovation, Investments, and Unbundling", Yale Journal of Regulation, 17, 1-37.

Kotakorpi, K., 2006, "Access Price Regulation, Investment and Entry in Telecommunications", International Journal of Industrial Organization, 24, 1013-1020.

Laffont, J.J., Tirole, J., 2000, "Competition in Telecommunications", MIT Press.

Martin, S., 2002, "Advanced Industrial Economics", Blackwell Publishers Ltd.

Phoenix Center Policy Bulletin, 2003a, "Competition and Bell Company Investment in Telecommunications Plant: The Effects of UNE-P, ${ }^{\circ} 5 "$.

Phoenix Center Policy Bulletin, 2003b, "Une-P Drives Bell Investment: A Synthesis Model, $n^{\circ} 6 "$.

Sappington, D., 2002, "Price Regulation and Incentives", In: Cave, M., Majumdar, S., Vogelsang, I. (Eds.), Handbook of Telecommunications Economics, vol. 1. North-Holland, Amsterdam, pp.227-293.

SidAK, G., and Spulber, D., 1997, "Deregulatory takings and the regulatory contract", Cambridge University Press.

Spence, A., 1976, "Product differentiation and welfare", American Economic Review, 66, 2, 407-414.

Valletti, T., 2003, "The Theory of Access Pricing and its Linkage with Investment Incentives", Telecommunications Policy, 27, 659-675.

VAreda, J., and Hoernig, S., 2007, "The race for telecoms infrastructure investment with bypass: Can access regulation achieve the first best?", CEPR Discussion Paper 6012.

Willig, R., Lehr, W., Bigelow, J., and Levinson, S., 2002, "Stimulating Investment and the Telecommunications Act of 1996", report filed by AT\&T in FCC Docket, 1-338. 